DOI: $10.34185 / 1991-7848.2018 .01 .01$

УДК 004:681.2.08

А.Ю. Зимогляд, А.И. Гуда, В.В. Ковтун

\title{
ИССЛЕДОВАНИЕ ФИЗИЧЕСКИХ ПРОЦЕССОВ НАНЕСЕНИЯ ЦИНКА ИЗ ПАРО-ГАЗОВОЙ ФАЗЫ В ВАКУУМЕ
}

\begin{abstract}
Термическое напыление активно применяется в микроэлектронике и оптике, в частности, методом делают напыление просветляющих и отражающих покрытий. Целью данной работы является исследование зависимости толщины металлических пленок от времени нанесения в вакууме. Для того, что бы узнать не сталкиваются ли атомы металла при испарении с молекулами остаточного газа в камере при своем движении к стеклянной подложке, а также что их траектория прямолинейна, посчитаем среднюю длину пробега молекулы. Если в вакуумной камере расстояние от испарителя до подложки достаточно мало, по сравнению со средней длиной пробега молекулы, то большая часть атомов металла будет достигать подложки не сталкиваясь, $c$ молекулами остаточного газа. Произведено ряд замеров сопротивления металлических пленок, полученных при напылении в вакуумеи выполнено исследование физических процессов нанесения цинка из парогазовой фазы в вакууме. На основании полученных экспериментальных данных было выявлено зависимость толщины металлических пленок от времени нанесения

Ключевые слова: вакуум, металлические пленки, термическое нанесение в вакууме.
\end{abstract}

\section{Введение и постановка задачи}

Термическое напыление металлических пленок в вакууме применяется для нанесения слоев металлизации. Примером применения металлических пленок может служить металлизированная упаковочная пленка для защиты от статики микросхем. Так же термическое напыление активно применяется в микроэлектронике и оптике. В оптике данным методом делают напыление просветляющих и отражающих покрытий.

Целью данной работы является исследование зависимости толщины металлических пленок от времени нанесения в вакууме.

\section{Основная часть}

При получении металлических пленок методом термического испарения в вакууме, атомы металла конденсируется на поверхности подложки. Для того, что бы узнать не сталкиваются ли атомы металла при испарении с молекулами остаточного газа в камере при своем движении к стеклянной подложке, а также что их траектория прямолинейна, посчитаем среднюю длину пробега молекулы. Если в вакуумной камере расстояние от испарителя до подложки достаточно мало, по сравнению со средней длиной пробега молекулы, то большая часть атомов металла будет достигать подложки не сталкиваясь, с молекулами остаточного газа.

Для расчета средней длины пробега молекул (1), для начала найдем концентрацию молекул при температуре - Т в Кельвинах и при давлении - Р в Па. В данной формуле $\mathrm{k}$ постоянная Больцмана.

$$
n=\frac{P}{k \times T}
$$

Воспользуюсь формулой (2), найдем среднюю длину пробега молекулы. В этой формуле используется полученная ранее концентрация молекул - n, а также эффективное сечение молекулы в квадрате. Так как в камере вакуумного поста для ионной очистки используется аргон, будет разумно применить его эффективное сечение. Эффективное сечение аргона 0,295 HM.

(c) Зимогляд А.Ю., Гуда А.И., Ковтун В.В., 2018 


$$
\lambda=\frac{1}{\sqrt{2} \times \pi \times \delta^{2} \times n}
$$

Для измерения давления внутри вакуумного поста ВУП - 4 используется термопарный манометр. Их принцип действия основан на охлаждении за счет теплопроводности. Термопара находится в контакте с нагреваемым проводом. Чем лучше вакуум, тем меньше теплопроводность газа, и следовательно выше температура проводника (теплопроводность разряженного газа прямо пропорциональна его давлению). Проградуировав подключенный к термопаре милливольтметр при известных давлениях, можно использовать измеряемое значение температуры для определения давления. В нашем случае использовался вакуумный термопарный манометр ПМТ - 2. У данного манометра полное отклонение стрелки 10 мВ при давлении 10(-4) мм. рт. ст., стоит учесть что зависимость давления к милливольтам нелинейная.

Напыление цинка на подложку осуществлялось при показании манометра в 6 мB, что соответствует приблизительно 3 Па. Температура внутри камеры может быть в диапазоне от $300 \mathrm{~K}$ до 1180 К (от комнатной до температуры тигеля, в которой плавится металл). Исходя из этого и формул (1) и (2) длина свободно пробега будет лежать в диапазоне 5 - 14 мм.

$$
K_{n}=\frac{\lambda}{a}
$$

Воспользовавшись формулой, для определения числа Кнудсена (3) получим значение меньше 1, так как расстояние между подложкой и испарителем 70 мм. Поскольку число Кнудсена меньше 1 , то нейтральные атомы металла при испарении сталкиваются с молекулами остаточного инертного газа по пути к подложки, и их траектория далека от прямолинейной. Фазовое состояние цинка в камере ближе к газовому.

Именно в таком фазовом состоянии происходило напыление цинка на стекло подложки, что было видно по однородному налету на прозрачном куполе вакуумного поста.

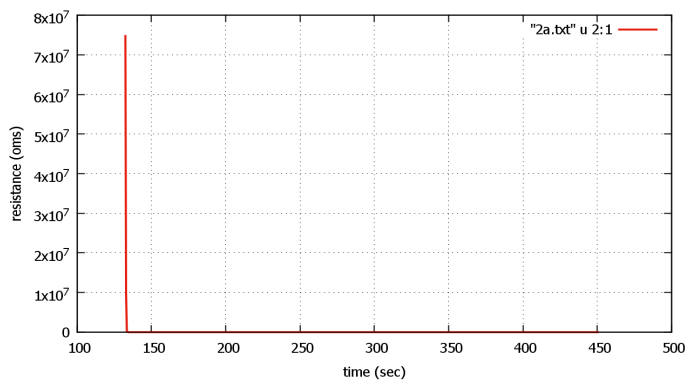

Рисунок 1 - Зависимость сопротивления пленки от времени нанесения

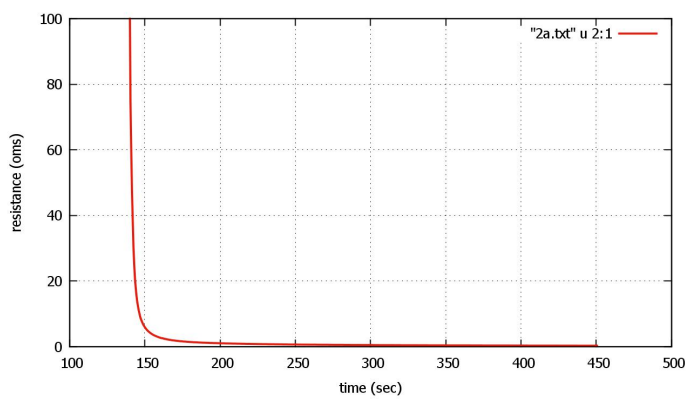

Рисунок 2 - Зависимость сопротивления пленки от времени нанесения при увеличенном масштабе

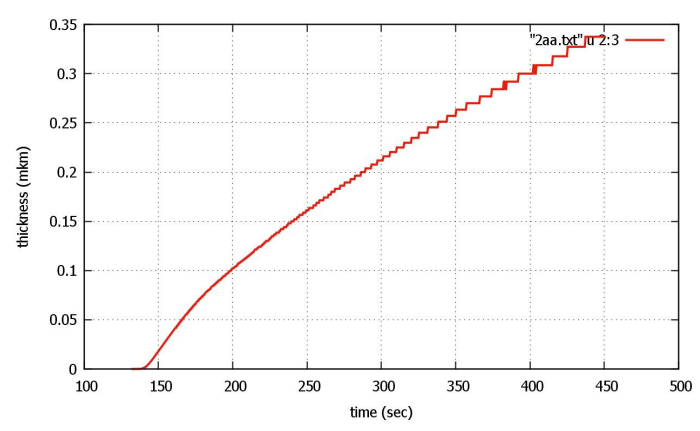

Рисунок 3 - Зависимость толщины металлической пленки от времени нанесения

Для нахождения зависимости времени напыления металла к толщине полученной пленки, был сделан датчик, который представлял собой прямоугольный отрезок текстолита, на 
котором было 2 медных полигона на расстоянии 10 мм, сам отрезок был длиной 20 мм. Данный датчик крепился рядом со стеклянной подложкой, и напыляемый металл конденсировался на нем так же, как и на стекле. Измерения проводились с мультиметром Ut61, в режиме измерения сопротивления. Сам же мультиметр через оптическую развязку, подключался к ноутбуку. На ноутбуке, с помощью написанной программы производилась привязка сопротивления к времени.

По полученным значениям были построены графики (рис.1,2).

По полученным сопротивлениям пленок, было посчитана их толщина в микрометрах с помощью формулы удельного сопротивления металла (4), а так же построен график зависимости толщины пленки цинка в микрометрах к времени нанесения в секундах (рис.3).

$$
r=\frac{P * l}{S}
$$

Ступеньки на графике вызваны дискретностью мультиметра, однако, не смотря на эти ступеньки, явно выделяется 2 области. Одна область линейная, вторая не линейная. В нелинейной области к тому же было более большое сопротивление при измерении, что указывает, скорее всего, на область формирования начальных точек конденсации, относительно которых потом формируется пленка. В это время атомы цинка мигрируют по поверхности подложки и при столкновении образуют скопления, которые по Фольмеру и Веберу называют зародышами. В этих зародышах между атомами действуют силы связи, определяемые энергией конденсации (центры конденсации), в результате происходит образование и рост зародышей. Чем больше скорость испарения, тем выше вероятность образования центров конденсации, обусловленных либо миграцией атомов по поверхности, либо столкновением с ранее осажденными атомами. В линейной же области графика происходит наращивание толщины пленки.

\section{Вывод}

Было произведено исследование физических процессов нанесения цинка из парогазовой фазы в вакууме. На основании полученных экспериментальных данных было выявлено зависимость толщины металлических пленок от времени нанесения. На графике зависимости было выявлено 2 области, нелинейная и линейная изменения толщины пленки. Полученные данные требуют дополнительного изучения.

\section{ЛИТЕРАТУРА}

1. Руденко В.С. Промислова електроніка: підручник / В.С. Руденко, В.Я. Ромашко, В.В. Трифонюк. - К.: Либідь, 1993. 432 с.

2. Хоровиц П. Мистецтво схемотехніки. Частина 2 / П. Хоровиц, У. Хилл. - М.: Мир,1995. - 371 с.

3. Райзер Ю.П. Физика газового разряда / Ю.П Райзер - М.: Наука, 1992. - 434c.

4. Хоровиц П. Искусство схемотехники. Часть 2 / П.Хоровиц, У. Хилл. - М.: Мир,1995. - 590 с.

5. Фейнман Р.П. Фейнмановские лекции по физике / Р.П. Фейнман, Р.Б. Лейтон. - Ч.5 - М.: Мир, 1977. $300 \mathrm{c.}$

6. Данилин Б.С. Применение низкотемпературной плазмы для нанесения тонких пленок / Б.С. Данилин // Энергоатомиздат, 1989. - 328 с.

7. Попов В. Ф. Процессы и установки электронноионной технологии/ В.Ф. Попов, Ю.Н. Горин // М.: Высш. шк., 1988. - 255 с.

8. Виноградов М.И. Вакуумные процессы и оборудование ионно - и электронно-лучевой технологии/ М.И. Виноградов, Ю.П. Маишев //

\section{REFERENCES}

1. Rudenko V.S. Promislova elektronIka: pIdruchnik / V.S. Rudenko, V.Ya. Romashko, V.V. Trifonyuk. - K.: LibId, 1993. $432 \mathrm{s.}$

2. Horovits P. Mistetstvo shemotehnIki. Chastina 2 / P. Horovits, U. Hill. - M.: Mir,1995. - 371 s.

3. Rayzer Yu.P. Fizika gazovogo razryada / Yu.P Rayzer - M.: Nauka, 1992. - 434s.

4. Horovits P. Iskusstvo shemotehniki. Chast $2 / \mathrm{P}$. Horovits, U. Hill. - M.: Mir,1995. - 590 s.

5. Feynman R.P. Feynmanovskie lektsii po fizike / R.P. Feynman, R.B. Leyton. - Ch.5 - M.: Mir, 1977. - 300 s. 6. Danilin B.S. Primenenie nizkotemperaturnoy plazmyi dlya naneseniya tonkih plenok / B.S. Danilin // Energoatomizdat, 1989. - $328 \mathrm{~s}$.

7. Popov V. F. Protsessyi i ustanovki elektronnoionnoy tehnologii/ V.F. Popov, Yu.N. Gorin // M.: Vyissh. shk., 1988. - 255 s.

8. Vinogradov M.I. Vakuumnyie protsessyi i oborudovanie ionno - i elektronno-luchevoy tehnologii/ M.I. Vinogradov, Yu.P. Maishev // M.: Mashinostroenie, 1989. - $56 \mathrm{~s}$. 
М.: Машиностроение, 1989. - 56 с.

\section{THE DEPENDENCE OF THICKNESS METALLIC FILMS TO THE TIME OF DEPOSITION OF THE RESULTING THERMAL EVAPORATION IN VACUUM}

Thermal spraying is actively used in microelectronics and optics, in particular, spraying of antireflective and reflective coatings is done by the method. The purpose of this work is to study the dependence of the thickness of metal films on the time of deposition in a vacuum. In order to find out whether the metal atoms collide with the evaporation of the residual gas molecules in the chamber as it moves towards the glass substrate, and also that their trajectory is straight, we calculate the average path length of the molecule. If the distance from the evaporator to the substrate in the vacuum chamber is sufficiently small compared to the average mean free path of the molecule, then most of the metal atoms will reach the substrate without colliding with the residual gas molecules. A number of measurements were made of the resistance of metal films obtained by sputtering in vacuum, and the physical processes of deposition of zinc from the vapor - gas phase were studied in vacuum. Based on the experimental data obtained, the dependence of the thickness of metal films on the time of deposition was revealed.

Keywords: vacuum, metallic films, thermal deposition in vacuum.

\section{ЗАЛЕЖНІСТЬ ТОВЩИНИ МЕТАЛЕВИХ ПЛІВОК ВІД ЧАСУ НАПИЛЕННЯМ У ВАКУУМІ}

Термічне напилення активно застосовується в мікроелектроніці і оптиці, зокрема, методом роблять напилення просвітлюють і відображають покриттів. Метою даної роботи $є$ дослідження залежності товщини металевих плівок від часу нанесення в вакуумі. Для того, що б дізнатися не стикаються чи атоми металу при випаровуванні з молекулами залишкового газу в камері при своєму русі до скляній підкладці, а також що їх траєкторія прямолінійна, порахуємо середню довжину пробігу молекули. Якщо у вакуумній камері відстань від випарника до підкладки досить мало, в порівнянні з середньою довжиною пробігу молекули, то велика частина атомів металу сягатиме підкладки не стикаючись, 3 молекулами залишкового газу. Вироблено ряд замірів опору металевих плівок, отриманих при напиленні в вакуумі виконано дослідження фізичних процесів нанесення цинку 3 парогазової фази у вакуумі. На підставі отриманих експериментальних даних було виявлено залежність товщини металевих плівок від часу нанесення

Ключові слова: вакуум, металеві плівки, термічне нанесення в вакуумі.

Зимогляд Андрій Юрійович - аспірант, кафедра інформаційних технологій та систем, Національна металургійна академія України.

Zimizhd Andriy - Postgraduate Student, Department of Information Technologies and Systems, National Metallurgical Academy of Ukraine.

Гуда Антон Ігоревич - к.т.н, доцент, кафедра інформаційних технологій та систем, Національна металургійна академія України.

Huda Anton - Candidate of Technical Sciences, Associate Professor, Department of Information Technologies and Systems, National Metallurgical Academy of Ukraine.

Ковтун Володимир Васильович - лаборант, кафедра інформаційних технологій та систем, Національна металургійна академія України.

Kovtun Volodymyr - laboratory assistant, department of information technologies and systems, National Metallurgical Academy of Ukraine. 